\title{
Influence of vascular endothelial growth factor single nucleotide polymorphisms on non-small cell lung cancer tumor angiogenesis
}

\author{
AI MAEDA, MASAO NAKATA, KOICHIRO YASUDA, TAKURO YUKAWA, \\ SHINSUKE SAISHO, RIKI OKITA, YUJI HIRAMI and KATSUHIKO SHIMIZU \\ Department of General Thoracic Surgery, Kawasaki Medical School, Kurashiki, Okayama 701-0192, Japan
}

Received June 27, 2012; Accepted August 30, 2012

DOI: $10.3892 /$ or.2012.2075

\begin{abstract}
Vascular endothelial growth factor (VEGF) plays an important role in tumor angiogenesis. Several studies have reported that genomic $V E G F$ polymorphisms may influence $V E G F$ synthesis. To evaluate the role of VEGF single nucleotide polymorphisms (SNPs), we examined the expression of several angiogenesis-related proteins [VEGF, hypoxiainducible factor- $1 \alpha$ (HIF- $1 \alpha$ ) and delta-like ligand 4 (Dl14)] and the spread of microvessels in resected non-small cell lung cancer (NSCLC). Blood and tumor tissue from 83 patients with NSCLC were examined for VEGF -460T/C (rs833061) and $V E G F+405 \mathrm{G} / \mathrm{C}$ (rs2010963) SNPs using the SNaPshot method. Immunohistochemical staining was performed to measure protein expression and microvessel density (MVD). $V E G F-460 \mathrm{~T} / \mathrm{C}$ and $+405 \mathrm{G} / \mathrm{C}$ SNPs showed no association with VEGF or HIF-1 $\alpha$ expression and MVD. Patients with $V E G F-460 \mathrm{TT}$ and the TC genotype had significantly higher MVD compared to those with the CC genotypes. Furthermore, patients with the $V E G F-460 T T$ genotype had significantly higher Dll4 expression compared to those with the TC or CC genotypes, while the $V E G F+405 \mathrm{G} / \mathrm{C}$ SNP displayed no association with Dll4 expression and MVD. These findings indicate that the $V E G F-460 \mathrm{~T} / \mathrm{C}$ SNP may have a functional influence on tumor angiogenesis in NSCLC. We hypothesize that VEGF SNPs may influence angiogenesis through Dll4.
\end{abstract}

\section{Introduction}

Angiogenesis plays an important role in tumor progression and metastasis, and vascular endothelial growth factor (VEGF) is a key component. Several studies have demonstrated that

Correspondence to: Dr Ai Maeda, Department of General Thoracic Surgery, Kawasaki Medical School, 577 Matsushima, Kurashiki, Okayama 701-0192, Japan

E-mail: amaeda@med.kawasaki-m.ac.jp

Key words: polymorphisms, angiogenesis, vascular endothelial growth factor, delta-like ligand 4
VEGF mRNA and protein overexpression are associated with tumor progression and prognosis in non-small cell lung cancer (NSCLC) (1-3).

Several $V E G F$ single nucleotide polymorphisms (SNPs) have been recently described (4). VEGF is located on chromosome $6 p 21.3$ and is organized into eight exons and seven introns $(5,6)$. The VEGF -460T/C SNP (rs833061) is located in the promoter region and may influence promoter activity (7). Furthermore, the VEGF +405G/C SNP (rs2010963) is located within the 5'-untranslated region and may affect transcription factor binding affinity $(7,8)$. These two SNPs have been investigated in different types of cancers, and the association of various VEGF SNPs with risk or prognosis of several cancers has been examined (9-12). Recently, $V E G F+405$ and -460 SNPs have been found to be significantly associated with risk and survival in NSCLC (13-15). However, the influence of $V E G F$ SNPs on tumor angiogenesis remains unclear. In this study, we examined whether VEGF -460 and +405 SNPs may influence VEGF expression and microvessel density (MVD) in NSCLC.

Tumor angiogenesis is influenced by a number of proteins. Hypoxia occurs early in tumor development and results in stable binding of hypoxia-inducible factor- $1 \alpha(\mathrm{HIF}-1 \alpha)$ to DNA and the activation of other angiogenic genes, such as VEGF (16,17). Delta-like ligand 4 (Dll4) is a ligand for Notch proteins that is expressed by endothelial cells $(18,19)$ and may be induced by VEGF and HIF-1 $\alpha$ (20). It plays an important role in tumor vessel maturation and remodeling $(21,22)$. Therefore, we studied whether these VEGF SNPs were associated with the expression of the angiogenesis-related proteins HIF1 $\alpha$ and D114.

\section{Patients and methods}

Study population. Blood and tumor samples were obtained from 83 patients with NCSLC who underwent surgical resection at the Kawasaki Medical School Hospital between October, 2008 and December, 2010. The patients did not receive radio- or chemotherapy before surgery. This study was approved by the Ethics Committee of the Kawasaki Medical School, and informed consent was obtained from all patients for the use of their tissue specimens. 


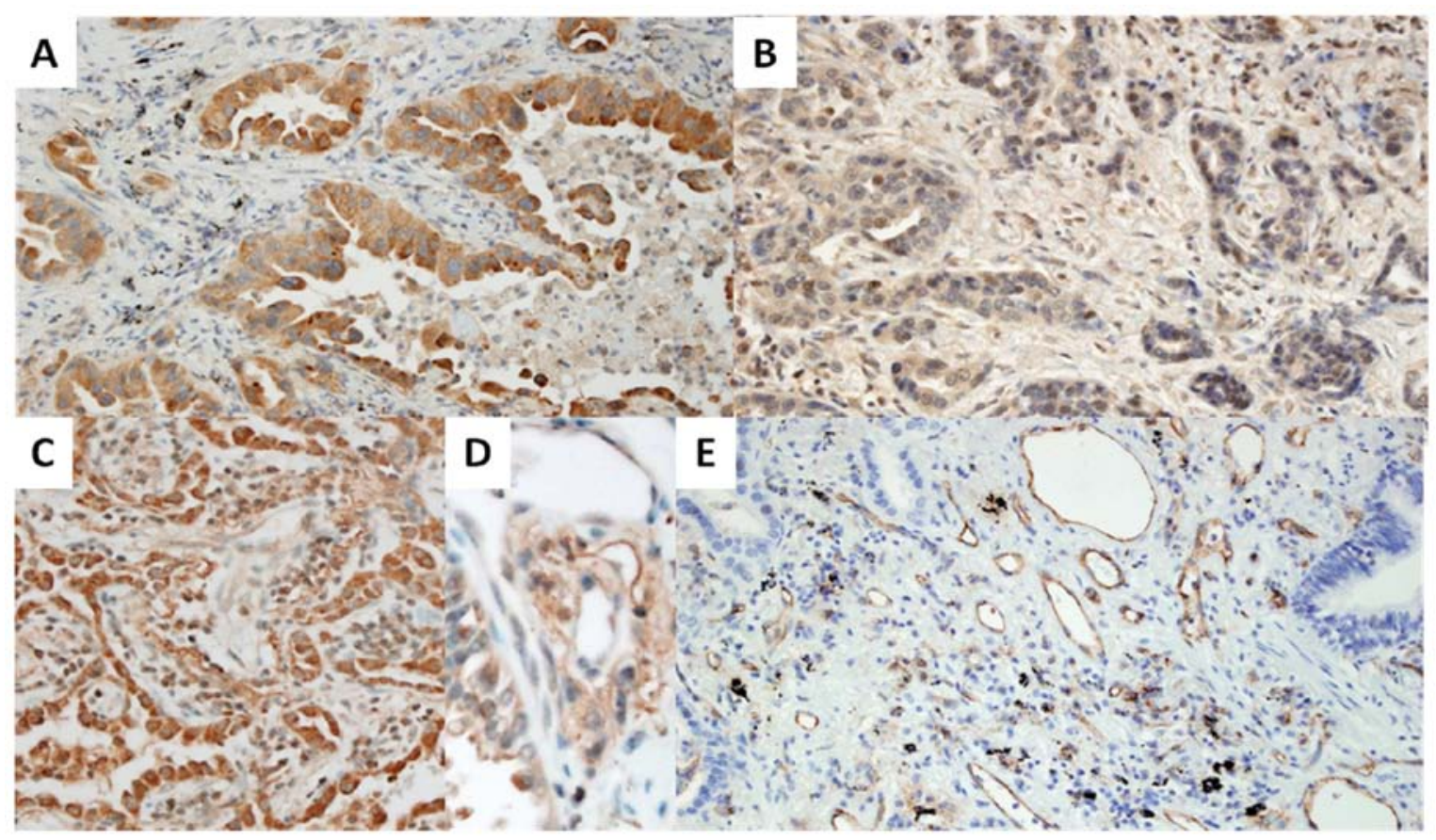

Figure 1. Positive immunohistochemical staining for (A) VEGF, (B) HIF-1a, (C) D114 (tumor cells), (D) D114 (endothelial cells), and (E) CD31 (for microvessel counting, x200 magnification).

Analysis of VEGF-A -460T/C and $+405 G / C$ polymorphisms. Blood samples were collected from all subjects before surgery. Genomic DNA was isolated from peripheral whole blood using the QIAamp ${ }^{\mathrm{TM}}$ DNA Blood Mini kit (Qiagen, Hilden, Germany). Genomic regions containing the VEGF -460T/C and $+405 \mathrm{G} / \mathrm{C}$ SNPs were amplified by polymerase chain reaction using the following primers: -460T/C, 5'-CGAGAGTGA GGACGTGTGTG-3' (forward) and 5'-ATTGGAATCCTG GAGTGACC-3' (reverse); +405G/C, 5'-GAGAGACGGGGT CAGAGAGA-3' (forward) and 5'-CCCAAAAGCAGGTCAC TCA-3' (reverse). The VEGF SNPs were genotyped by a single-base primer extension assay using the $\mathrm{SNaPshot}{ }^{\mathrm{TM}}$ Multiplex kit (Applied Biosystems, Foster City, CA, USA), according to the manufacturer's instructions. The following primers were used: -460T/C, 5 '-tttttttCTTCTCCCCGCTCCAAC-3'; +405G/C, 5'-tttttttttttttGTGCGAGCAGCGA AAG-3'.

DNA sequencing. Polymorphism analysis was performed using the ABI PRISM ${ }^{\circledR} 310$ Genetic Analyzer, and results were evaluated using GeneMapper ${ }^{\circledR}$ software, ver. 4.1 (all were from Applied Biosystems).

Immunohistochemical staining. VEGF, HIF-1 $\alpha$,D114 and CD31 (to measure MVD) expression was analyzed using resected, paraffin-embedded lung cancer tissue. After microtome sectioning (4- $\mu \mathrm{m}$ thick), tissue slides were processed on an automated immunostainer (NexES; Ventana Medical Systems, Tucson, AZ, USA) or manual methods. Streptavidin-biotinperoxidase detection was performed with diaminobenzidine as the chromogen. The following primary antibodies were used according to the manufacturer's instructions: VEGF (rabbit polyclonal; sc-152; 1:300 dilution; Santa Cruz Biotechnology,
Inc., Santa Cruz, CA, USA), HIF-1 $\alpha$ (mouse monoclonal; ESEE122; 1:1,000 dilution; Novus, Littleton, CO, USA), D114 (rabbit polyclonal; ab7280; 1:50 dilution; Abcam, Cambridge, MA, USA), and CD31 (mouse monoclonal; 1:50 dilution; Dako, Carpinteria, CA, USA). The slides were examined by two investigators blinded to the corresponding clinicopathological data. The expression of each protein marker was examined and evaluated according to previously reported protocols $(1,23-26)$.

VEGF staining and scoring. To evaluate VEGF expression, the percentage of positively stained cells and staining intensity were scored as follows: grade 0 , negative; grade 1 , weak; grade 2, moderate; grade 3, high; and grade 4, very high (23). Grade 0 indicated staining intensity equal to the negative control, grade 3 indicated intensity equal to the positive control, and grade 4 indicated intensity higher than the positive control. Stain intensity in the cell cytoplasm was similarly scored (23). To determine the percentage of cells with the various staining intensities, the number of immunoreactive cells at each intensity was divided by the total number of tumor cells in three fields at x200 magnification (Fig. 1A). The overall VEGF staining score was calculated as follows: VEGF score $=1 \times$ percentage of grade 1 cells $+2 \times$ percentage of grade 2 cells $+3 \times$ percentage of grade 3 cells $+4 \times$ percentage of grade 4 cells. The score was analyzed as a continuous and a dichotomous variable.

HIF-1 $\alpha$ staining and scoring. Tumor cells were scored on the intensity and extent of staining as follows: score 1, tumor cells with absent or weak cytoplasmic reactivity and no nuclear reactivity; score 2, tumor cells with moderate/strong cytoplasmic reactivity with a percentage of tumor cells less than their mean percentage and no nuclear reactivity; score 3 , tumor cells with moderate/strong cytoplasmic reactivity with 
Table I. Characteristics of the patients with NSCLC.

\begin{tabular}{|c|c|c|}
\hline Characteristic & No. of patients & $\%$ \\
\hline \multicolumn{3}{|l|}{ Age (years) } \\
\hline Median & 72 & \\
\hline Range & $49-89$ & \\
\hline \multicolumn{3}{|l|}{ Gender } \\
\hline Male & 52 & 62.7 \\
\hline Female & 31 & 37.3 \\
\hline \multicolumn{3}{|l|}{ Smoking } \\
\hline Never & 27 & 32.5 \\
\hline Former/Current & 56 & 67.5 \\
\hline \multicolumn{3}{|l|}{ Stage } \\
\hline IA & 40 & 48.2 \\
\hline IB & 17 & 20.5 \\
\hline IIA & 11 & 13.3 \\
\hline IIB & 9 & 10.8 \\
\hline III & 6 & 7.2 \\
\hline \multicolumn{3}{|l|}{ Histology } \\
\hline Adenocarcinoma & 52 & 62.7 \\
\hline $\mathrm{SCC}$ & 19 & 22.9 \\
\hline Other types & 12 & 14.4 \\
\hline
\end{tabular}

SCC, squamous cell carcinoma; NSCLC, non-small cell lung cancer.

a percentage of tumor cells more than their mean percentage; score 4 , tumor cells with clear nuclear reactivity (with or without cytoplasmic reactivity regardless of the intensity) (Fig. 1B). Tumors with scores of 1 and 2 were considered to exhibit low HIF-1 $\alpha$ expression, whereas those with scores of 2 and 3 were considered to exhibit high HIF-1 $\alpha$ expression (24).

Dll4 staining and scoring. Dll4 expression was considered only in endothelial cells, although recent reports have demonstrated its wide cellular distribution beyond vessels $(25,26)$. To evaluate Dll4 staining in tumor cells (Fig. 1C and D), the intensity of expression was scored on a semiquantitative scale in three $\times 200$ magnification fields. Negative cores were scored as 0 , cores with weak expression were scored as 1 and those with moderate/strong expression were scored as 2. High D114 expression was defined as a score greater than 1.5 (26).

Microvessel staining and counting. MVD was assessed by counting the number of microvessels stained for CD31. Vessels with a clearly defined lumen or well-defined linear vessel shape and no single endothelial cells were selected for counting. Microvessels were counted in the three x200 magnification fields with the highest density (Fig. 1E), and the mean MVD was calculated (1).

Statistical analysis. Vascular scores were presented as the means \pm standard deviation and the difference between the groups was analyzed using the unpaired Student's t-test. The association of VEGF SNPs with clinicopathological
Table II. Relationships between angiogenesis related protein expression as determined by immunohistochemistry.

\begin{tabular}{|c|c|c|c|c|}
\hline \multirow[b]{2}{*}{ Variable } & \multicolumn{2}{|c|}{ VEGF } & \multicolumn{2}{|c|}{ HIF- $1 \alpha$} \\
\hline & High & Low & High & Low \\
\hline \multicolumn{5}{|l|}{ HIF- $1 \alpha$} \\
\hline High & 29 & 15 & & \\
\hline Low & 13 & 26 & & \\
\hline P-value & \multicolumn{2}{|c|}{$\mathrm{P}=0.003$} & & \\
\hline \multicolumn{5}{|l|}{ DLL4 (T) } \\
\hline High & 27 & 23 & 34 & 16 \\
\hline Low & 15 & 18 & 10 & 23 \\
\hline $\mathrm{P}$-value & \multicolumn{2}{|c|}{$\mathrm{P}=0.446$} & \multicolumn{2}{|c|}{$\mathrm{P}<0.001$} \\
\hline
\end{tabular}

VEGF, vascular endothelial growth factor; Dll4, delta-like ligand 4; HIF- $1 \alpha$, hypoxia-inducible factor- $1 \alpha$; T, tumor cells.

parameters and immunostaining results was examined using Chi-squared and Fisher's exact tests, respectively. The level of significance was set at $\mathrm{P}<0.05$. All analyses were performed using SPSS software (version 17.0; SPSS, Chicago, IL, USA).

\section{Results}

Clinical characteristics. Characteristics of the patients with NSCLC are summarized in Table I. Patients ranged in age from 49 to 89 years (median, 72 years), with 52 men and 31 women. Fifty-six (67.5\%) patients were former/current smokers. There were 40 (48.2\%) stage IA, 17 (20.5\%) stage IB, $11(13.3 \%)$ stage IIA, $9(10.8 \%)$ stage IIB, $6(7.2 \%)$ stage III. Fifty-two (62.7\%) patients had adenocarcinoma, $19(22.9 \%)$ had squamous cell carcinoma, and 12 (14.4\%) had other histological malignancies.

Immunohistochemistry of angiogenesis-related proteins. Forty-two patients (50.6\%) exhibited a marked increase in VEGF immunoreactivity of tumor cells. The mean VEGF staining score was $2.79 \pm 0.67$, and the median score of 2.90 was used to distinguish between low and high VEGF staining. VEGF expression was correlated with HIF1 $\alpha$ expression $(\mathrm{P}=0.003)$, but not with Dll4 expression $(\mathrm{P}=0.446)$ (Table II).

VEGF SNPs and clinicopathological characteristics. For the $V E G F+405 \mathrm{G} / \mathrm{C}$ SNP, $50.6 \%$ of patients had the GC genotype, $25.3 \%$ had CC and $24.1 \%$ had GG. For the VEGF -460T/C SNP, $50.6 \%$ had the TT genotype, $38.6 \%$ had TC and $10.8 \%$ had CC. No significant association was observed between $V E G F$ SNPs and clinicopathological characteristics such as gender, pathological stage, lymphatic invasion, vascular invasion, histological type, and smoking status (Table III).

VEGF SNPs and angiogenesis-related proteins. Both SNPs displayed no association with VEGF or HIF-1 $\alpha$ expression; however, Dll4 expression was significantly higher in patients with the VEGF-460TT genotype $(\mathrm{P}=0.031)$ (Table IV). 
Table III. VEGF SNPs and clinicopathological characteristics.

\begin{tabular}{|c|c|c|c|c|c|c|c|c|}
\hline \multirow[b]{2}{*}{ Characteristic } & \multicolumn{4}{|c|}{$V E G F+405$ genotype } & \multicolumn{4}{|c|}{$V E G F-460$ genotype } \\
\hline & $\mathrm{CC}$ & $\mathrm{GC}$ & GG & P-value & $\mathrm{TT}$ & $\mathrm{TC}$ & $\mathrm{CC}$ & P-value \\
\hline $\begin{array}{l}\text { No. of patients } \\
(\%)\end{array}$ & $\begin{array}{c}21 \\
(25.3)\end{array}$ & $\begin{array}{c}42 \\
(50.6)\end{array}$ & $\begin{array}{c}20 \\
(24.1)\end{array}$ & & $\begin{array}{c}42 \\
(50.6)\end{array}$ & $\begin{array}{c}32 \\
(38.6)\end{array}$ & $\begin{array}{c}9 \\
(10.8)\end{array}$ & \\
\hline \multicolumn{9}{|l|}{ Gender } \\
\hline Male & 15 & 23 & 14 & 0.321 & 23 & 21 & 8 & 0.143 \\
\hline Female & 6 & 19 & 6 & & 19 & 11 & 1 & \\
\hline \multicolumn{9}{|l|}{ Stage } \\
\hline IA & 11 & 19 & 10 & 0.807 & 21 & 14 & 5 & 0.481 \\
\hline IB & 5 & 8 & 4 & & 7 & 8 & 2 & \\
\hline II & 3 & 11 & 6 & & 9 & 10 & 1 & \\
\hline III & 2 & 4 & 0 & & 5 & 0 & 1 & \\
\hline \multicolumn{9}{|l|}{ Lymphatic invasion } \\
\hline+ & 5 & 10 & 3 & 0.707 & 10 & 6 & 2 & 0.871 \\
\hline- & 16 & 32 & 17 & & 32 & 26 & 7 & \\
\hline \multicolumn{9}{|l|}{ Vascular invasion } \\
\hline+ & 10 & 15 & 8 & 0.661 & 19 & 10 & 4 & 0.455 \\
\hline- & 11 & 27 & 12 & & 23 & 22 & 4 & \\
\hline \multicolumn{9}{|l|}{ Histology } \\
\hline Adenocarcinoma & 12 & 27 & 13 & 0.522 & 26 & 21 & 5 & 0.688 \\
\hline SCC & 8 & 8 & 3 & & 8 & 8 & 3 & \\
\hline Other types & 1 & 7 & 4 & & 8 & 3 & 1 & \\
\hline \multicolumn{9}{|l|}{ Smoking } \\
\hline Never & 7 & 14 & 6 & 0.962 & 17 & 6 & 4 & 0.102 \\
\hline Former/current & 14 & 28 & 14 & & 25 & 26 & 5 & \\
\hline
\end{tabular}

$V E G F$, vascular endothelial growth factor; SCC, squamous cell carcinoma.

Table IV. VEGF SNPs and angiogenic-related protein expression.

\begin{tabular}{|c|c|c|c|c|c|c|c|c|c|}
\hline \multirow{2}{*}{$\begin{array}{l}V E G F \\
\text { Genotype }\end{array}$} & \multicolumn{3}{|c|}{ VEGF } & \multicolumn{3}{|c|}{ HIF- $1 \alpha$} & \multicolumn{3}{|c|}{ Dll4 } \\
\hline & High & Low & P-value & High & Low & P-value & High & Low & $\mathrm{P}$-value \\
\hline \multicolumn{10}{|c|}{$V E G F+405$} \\
\hline $\mathrm{CC}$ & 12 & 9 & 0.735 & 10 & 11 & 0.739 & 12 & 9 & 0.741 \\
\hline GC & 21 & 21 & & 24 & 18 & & 27 & 15 & \\
\hline GG & 9 & 11 & & 10 & 10 & & 11 & 9 & \\
\hline \multicolumn{10}{|l|}{$V E G F-460$} \\
\hline TT & 19 & 23 & 0.448 & 21 & 21 & 0.289 & 31 & 11 & 0.031 \\
\hline $\mathrm{TC}$ & 19 & 13 & & 16 & 16 & & 14 & 18 & \\
\hline $\mathrm{CC}$ & 4 & 5 & & 7 & 2 & & 5 & 4 & \\
\hline
\end{tabular}

Dll4, delta-like ligand 4; HIF-1 $\alpha$, hypoxia-inducible factor-1 $\alpha$; $V E G F$, vascular endothelial growth factor.

Angiogenesis-related proteins and MVD. MVD ranged from 2.0 to 80.0 , with a mean value of $29.9 \pm 15.9$ and a median score of 29. High MVD was significantly associated with high VEGF $(\mathrm{P}<0.001)$ and Dll4 $(\mathrm{P}=0.026)$ expression, but not with HIF-1 $\alpha$ expression $(\mathrm{P}=0.235)$ (Table $\mathrm{V})$.
VEGF SNPs and MVD. Patients with the VEGF -460TT and TC genotypes had significantly greater MVD compared to those with the $\mathrm{CC}$ genotype (TT/TC vs. $\mathrm{CC} ; \mathrm{P}=0.027$ ) (Table VIA). Moreover, in a group of tumors with high VEGF expression, patients with the VEGF -460TT genotype 
Table V. Angiogenesis-related protein expression and MVD.

\begin{tabular}{llr}
\hline & \multicolumn{2}{c}{ MVD } \\
\cline { 2 - 3 } $\begin{array}{l}\text { Protein marker } \\
\text { expression }\end{array}$ & Mean \pm SD & P-value \\
\hline VEGF & & \\
High & $37.2 \pm 18.0$ & $<0.001$ \\
Low & $24.3 \pm 11.7$ & \\
Dll4 (T) & & 0.026 \\
High & $33.9 \pm 17.4$ & \\
Low & $26.1 \pm 13.9$ & \\
HIF-1 $\alpha$ & & 0.235 \\
High & $32.9 \pm 16.5$ & \\
Low & $28.5 \pm 16.3$ &
\end{tabular}

VEGF, vascular endothelial growth factor; Dll4, delta-like ligand 4; HIF- $1 \alpha$, hypoxia-inducible factor- $1 \alpha$; MVD, microvessel density; $\mathrm{SD}$, standard deviation; $\mathrm{T}$, tumor cells.

Table VI. VEGF SNPs and MVD.

\section{A, VEGF SNPs and MVD}

\begin{tabular}{llc}
\hline & \multicolumn{2}{c}{ MVD } \\
\cline { 2 - 3 } Genotype & Mean \pm SD & P-value \\
\hline$V E G F+405$ & & \\
CC & $27.3 \pm 17.0$ & CC/GC vs. GG 0.426 \\
GC & $31.9 \pm 16.4$ & GG/GC vs. CC 0.961 \\
GG & $28.8 \pm 14.0$ & \\
$V E G F-460$ & & \\
TT & $31.9 \pm 18.1$ & TC/CC vs. TT 0.550 \\
TC & $31.4 \pm 16.0$ & TT/TC vs. CC 0.027 \\
CC & $23.9 \pm 7.8$ & \\
\hline
\end{tabular}

B, VEGF SNPs and MVD in the high VEGF expression group

\begin{tabular}{llr}
\hline & \multicolumn{2}{c}{ MVD } \\
\cline { 2 - 3 } Genotype & Mean $\pm \mathrm{SD}$ & P-value \\
\hline$V E G F+405$ & & CC/GC vs. GG 0.392 \\
CC & $36.75 \pm 19.16$ & CC vs. GG 0.615 \\
GC & $39.48 \pm 18.14$ & \\
GG & $32.67 \pm 17.29$ & TT/TC vs. CC 0.032 \\
$V E G F-460$ & & TT vs. CC 0.033 \\
TT & $40.05 \pm 19.77$ & \\
TC & $36.63 \pm 17.54$ & \\
CC & $26.75 \pm 6.85$ & \\
\hline
\end{tabular}

MVD, microvessel density; SD, standard deviation; VEGF, vascular endothelial growth factor. had significantly higher MVD compared to those with the $\mathrm{CC}$ genotypes $(\mathrm{P}=0.033)$ (Table VIB).

\section{Discussion}

Angiogenesis is important for tumor progression and utilizes several factors, with VEGF being the key factor. Recently, several VEGF SNPs have been identified, and their effect has attracted a great deal of attention. An in vivo study by Stevens et al (7) discovered that VEGF -460/+405 SNPs significantly altered VEGF promoter activity in response to phorbol esters. Recent literature has reported the association of VEGF SNPs with risk or prognosis of various types of cancers (9-12). A large case-control study in Caucasians demonstrated that male patients with NSCLC and the VEGF $+405 \mathrm{CC}+\mathrm{CG}$ genotype had a higher risk of lung adenocarcinoma, while those with the $-460 \mathrm{~T} /+405 \mathrm{G} / 936 \mathrm{C}$ haplotype had a reduced risk. (14). The $\mathrm{C}$ allele of the $V E G F+405 \mathrm{G} / \mathrm{C} \mathrm{SNP}$ significantly improved survival in early-stage NSCLC (13), whereas the -460CC genotype decreased overall survival in advanced-stage NSCLC (15). Other studies have suggested a lower survival rate for the $V E G F+405 C C$ genotype in gastric and ovarian cancers $(27,28)$. The reason for these conflicting results is currently unclear, and the influence of VEGF SNPs remains uncertain and controversial.

However to date, few studies have focused on the association between VEGF SNPs and VEGF expression. Therefore, we conducted a study with NSCLC patients to examine the functional activity of VEGF SNPs and their possible role in VEGF expression and angiogenesis.

The genotype frequencies for $V E G F+405 \mathrm{G} / \mathrm{C}(\mathrm{GG}$, $\mathrm{CC}$, and GC) and $V E G F-460 \mathrm{~T} / \mathrm{C}$ (TT, CC and TC) SNPs in this study were equivalent to previous reports involving Japanese patients $(4,15)$. In our current study, there was no association between VEGF SNPs and VEGF expression. Koukourakis et al (29) reported that VEGF SNPs were associated with VEGF expression in NSCLC tumor cells and tumor angiogenic activity. They discovered that the $V E G F-2578 \mathrm{CC}$, +405GG (also referred to as -634GG) -1154AA and GA genotypes were associated with low VEGF expression in 36 patients with NSCLC (29). The vascular density of patients with the $V E G F-2578 \mathrm{CC}$ and $+405 \mathrm{GG}$ genotypes was also significantly lower compared to that in patiens with other genotypes. This result is not in agreement with our findings, which may be due to variations in genotype function related to racial differences between the patient groups.

We discovered that patients with the VEGF-460TT and TC genotype had significantly higher MVD compared to those with CC genotypes. In general, as in our study, high VEGF expression is associated with high vascular density. However, there was no association between the VEGF -460T/C SNP and VEGF expression in tumors. Furthermore, even in high VEGF expression cases, the -460TT genotype was associated with significantly higher MVD compared to CC genotype. This result suggested that high MVD in -460TT genotype was not caused by VEGF expression. The VEGF-460TT genotype was associated with significantly higher Dll4 protein expression, which demonstrated a significant association with high MVD. From these results, we concluded that Dll4, induced by the $V E G F-460 \mathrm{TT}$ genotype, influenced the spread of microves- 
sels. D114 is generally upregulated by VEGF, which in turn acts as a negative feedback regulator of VEGF. Our results suggest that VEGF SNPs may influence VEGF downstream signaling to Dll4, although potential mechanisms have not been examined in this study. Dll4 is associated with tumor vessel maturation and remodeling $(21,22)$. Thus, high D114 expression should theoretically lead to fewer but larger vessels, and D114 overexpression or inhibition may consequently impair tumor angiogenesis. However, further study of this visceral function is warranted.

In conclusion, the $V E G F-460 \mathrm{~T} / \mathrm{C}$ SNP may have a functional influence on tumor angiogenesis in NSCLC. Although $V E G F$ SNPs were not associated with VEGF expression in tumor cells, they are considered to regulate the response to Dll4 signaling through functional changes in VEGF.

\section{Acknowledgements}

This study was supported in part by a Research Project Grant (no. 20-108N, 21-116, 23G-2) from Kawasaki Medical School.

\section{References}

1. Yuan A, Yu CJ, Chen WJ, Lin FY, Kuo SH, Luh KT and Yang PC: Correlation of total VEGF mRNA and protein expression with histologic type, tumor angiogenesis, patient survival and timing of relapse in non-small-cell lung cancer. Int J Cancer 89: 475-483, 2000.

2. Han H, Silverman JF, Santucci TS, et al: Vascular endothelial growth factor expression in stage I non-small cell lung cancer correlates with neoangiogenesis and a poor prognosis. Ann Surg Oncol 8: 72-79, 2001.

3. Kaya A, Ciledag A, Gulbay BE, et al: The prognostic significance of vascular endothelial growth factor levels in sera of non-small cell lung cancer patients. Respir Med 98: 632-636, 2004.

4. Jain L, Vargo CA, Danesi R, Sissung TM, Price DK, Venzon D, Venitz J and Figg WD: The role of vascular endothelial growth factor SNPs as predictive and prognostic markers for major solid tumors. Mol Cancer Ther 8: 2496-2508, 2009.

5. Brogan IJ, Khan N, Isaac K, Hutchinson JA, Pravica V and Hutchinson IV: Novel polymorphisms in the promoter and 5 UTR regions of the human vascular endothelial growth factor gene. Hum Immunol 60: 1245-1249, 1999.

6. Tischer E, Mitchell R, Hartman T, Silva M, Gospodarowicz D, Fiddes JC and Abraham JA: The human gene for vascular endothelial growth factor. Multiple protein forms are encoded through alternative exon splicing. J Biol Chem 266: 11947-11954, 1991.

7. Stevens A, Soden J, Brenchely PE, Ralph S and Ray DW: Haplotype analysis of the polymorphic human vascular endothelial growth factor gene promoter. Cancer Res 63: 812-816, 2003.

8. Watson CJ, Webb NJ, Bottomley MJ and Brenchley PE: Identification of polymorphisms within the vascular endothelial growth factor (VEGF) gene: correlation with variation in VEGF protein production. Cytokine 12: 1232-1235, 2000.

9. Lin CC, Wu HC, Tsai FJ, Chen HY and Chen WC: Vascular endothelial growth factor gene-460 $\mathrm{C} / \mathrm{T}$ polymorphism is a biomarker for prostate cancer. Urology 62: 374-377, 2003.

10. Ku KT, Wan L, Peng HC, Tsai MH, Tsai CH and Tsai FJ: Vascular endothelial growth factor gene- $460 \mathrm{C} / \mathrm{T}$ polymorphism is a biomarker for oral cancer. Oral Oncol 41: 497-502, 2005.

11. Lu H, Shu XO, Cui Y, et al: Association of genetic polymorphisms in the VEGF gene with breast cancer survival. Cancer Res 65: 5015-5019, 2005.
12. Kim JG, Chae YS, Sohn SK, et al: Vascular endothelial growth factor gene polymorphisms associated with prognosis for patients with colorectal cancer. Clin Cancer Res 14: 62-66, 2008.

13. Heist RS, Zhai R, Liu G, et al: VEGF polymorphisms and survival in early-stage non-small-cell lung cancer. J Clin Oncol 26: 856-862, 2008

14. Zhai R, Liu G, Zhou W, et al: Vascular endothelial growth factor genotypes, haplotypes, gender, and the risk of non-small cell lung cancer. Clin Cancer Res 14: 612-617, 2008.

15. Masago K, Fujita S, Kim YH, et al: Effect of vascular endothelial growth factor polymorphisms on survival in advanced-stage non-small-cell lung cancer. Cancer Sci 100: 1917-1922, 2009.

16. Ferrara N: VEGF and the quest for tumour angiogenesis factors. Nat Rev Cancer 2: 795-803, 2002.

17. Forsythe JA, Jiang BH, Iyer NV, Agani F, Leung SW, Koos RD and Semenza GL: Activation of vascular endothelial growth factor gene transcription by hypoxia-inducible factor 1 . Mol Cell Biol 16: 4604-4613, 1996.

18. Thurston G, Noguera-Troise I and Yancopoulos GD: The Delta paradox: DLL4 blockade leads to more tumour vessels but less tumour growth. Nat Rev Cancer 7: 327-331, 2007.

19. Indraccolo S, Minuzzo S, Masiero M, et al: Cross-talk between tumor and endothelial cells involving the Notch3-Dll4 interaction marks escape from tumor dormancy. Cancer Res 69: 1314-1323, 2009.

20. Patel NS, Li JL, Generali D, Poulsom R, Cranston DW and Harris AL: Up-regulation of delta-like 4 ligand in human tumor vasculature and the role of basal expression in endothelial cell function. Cancer Res 65: 8690-8697, 2005.

21. Hainaud P, Contrerès JO, Villemain A, Liu LX, Plouët J, Tobelem G and Dupuy E: The role of the vascular endothelial growth factor-Delta-like 4 ligand/Notch4-ephrin B2 cascade in tumor vessel remodeling and endothelial cell functions. Cancer Res 66: 8501-8510, 2006.

22. Patel NS, Dobbie MS, Rochester M, Steers G, Poulsom R, Le Monnier K, Cranston DW, Li JL and Harris AL: Up-regulation of endothelial delta-like 4 expression correlates with vessel maturation in bladder cancer. Clin Cancer Res 12: 4836-4844, 2006.

23. Fontanini G, Vignati S, Boldrini L, et al: Vascular endothelial growth factor is associated with neovascularization and influences progression of non-small cell lung carcinoma. Clin Cancer Res 3: 861-865, 1997.

24. Giatromanolaki A, Koukourakis MI, Sivridis E, et al: Relation of hypoxia inducible factor 1 alpha and 2 alpha in operable non-small cell lung cancer to angiogenic/molecular profile of tumours and survival. Br J Cancer 85: 881-890, 2001.

25. Martinez JC, Müller MM, Turley H, et al: Nuclear and membrane expression of the angiogenesis regulator delta-like ligand 4 (DLL4) in normal and malignant human tissues. Histopathology 54: 598-606, 2009.

26. Donnem T, Andersen S, Al-Shibli K, Al-Saad S, Busund LT and Bremnes RM: Prognostic impact of Notch ligands and receptors in nonsmall cell lung cancer: coexpression of Notch-1 and vascular endothelial growth factor-A predicts poor survival. Cancer 116: 5676-5685, 2010.

27. Tzanakis N, Gazouli M, Rallis G, et al: Vascular endothelial growth factor polymorphisms in gastric cancer development, prognosis, and survival. J Surg Oncol 94: 624-630, 2006.

28. Hefler LA, Mustea A, Könsgen D, et al: Vascular endothelial growth factor gene polymorphisms are associated with prognosis in ovarian cancer. Clin Cancer Res 13: 898-901, 2007

29. Koukourakis MI,Papazoglou D, Giatromanolaki A, Bougioukas G, Maltezos E and Sivridis E: VEGF gene sequence variation defines VEGF gene expression status and angiogenic activity in non-small cell lung cancer. Lung Cancer 46: 293-298, 2004. 